\title{
Mine or Theirs, Where Do Users Go? A Comparison of E-journal Usage at the OhioLINK Electronic Journal Center Platform versus the Elsevier ScienceDirect Platform
}

\begin{abstract}
:
This research provides librarians with a model for assessing and predicting which platforms patrons will use to access the same content, specifically comparing usage at the OhioLINK Electronic Journal Center (EJC) and at Elsevier's ScienceDirect from 2007 to 2013. Findings show that in the earlier years, the EJC was frequented more than ScienceDirect, but over time, users have gravitated to ScienceDirect over the EJC at a significantly higher rate. In addition, the data shows that the higher use of ScienceDirect began prior to and only grew after a devastating platform failure of the EJC in 2009.
\end{abstract}

\section{Publication Date:}

March 24, 2015

\section{Author Note:}

Juleah Swanson

Acquisitions Librarian for Electronic Resources, Assistant Professor

Ohio State University Libraries

$\underline{\text { Swanson.234@osu.edu }}$

\section{Publication Note:}

This is an electronic version of an article published in:

Swanson, J. (2015). Mine or Theirs, Where do Users Go? A comparison of E-journal Usage at the OhioLINK Electronic Journal Center platform versus Elsevier ScienceDirect platform. Journal of Electronic Resources Librarianship, 27(1), 1-9. http://www.tandfonline.com/doi/abs/10.1080/1941126X.2015.999514\#.VSvgffnF98E

Article in the Journal of Electronic Resources Librarianship is available at http://www.tandfonline.com/doi/abs/10.1080/1941126X.2015.999514\#.VSvgffnF98E 
With the inclusion of digital content in library collections, questions in collection development not only include what content to buy, but also how and where is content hosted. In the digital environment, content can be accessed on a variety of platforms hosted by a wide range of entities. Publishers can host their own content on their own platforms, such as Elsevier's ScienceDirect; or third-party distributors can host content online, such as ingentaconnect from Publishing Technology; or libraries and consortia can host content locally for their patrons such as OhioLINK's Electronic Journal Center.

In the late 1990s, when e-journals were starting to come online, two entities, a publisher and a library consortium, began to think independently about how to integrate digital content into library collections. The library consortium, OhioLINK, created the Electronic Journal Center, a locally hosted, one-stop shop for users to access e-journal content acquired by the consortium. Meanwhile, Elsevier developed ScienceDirect, a platform where customers and users could find and access Elsevier journals and articles. What has resulted since that time is the creation of two platforms that host journals and provide access to the same content subscribed to by OhioLINK. Though previous research has discussed the early successes of usage at OhioLINK's Electronic Journal Center, very little research has looked at use of locally hosted platforms in more recent years, since the rise of publisher-developed journal platforms. This paper will explore electronic journal usage in more recent years and examine where users tend to go when faced with a choice to access the same content on a publisher-hosted platform or a locally hosted platform.

\section{History of the OhioLINK Electronic Journal Center}

The Electronic Journal Center (EJC) is an online, locally-hosted platform and archive for journals purchased by the Ohio Library and Information Network (OhioLINK), a consortium of 
Ohio colleges and university libraries. The EJC provides online access to journal articles for users affiliated with institutions that are members of OhioLINK. As of June 2011, "a total of 39.5 million articles have been downloaded from the EJC since its inception in April 1998" (OhioLink, 2011, para. 3).

In 1995, OhioLINK began to consider the shared challenges members faced, notably the increasing cost of journal subscriptions; the availability of citation database, which drove up demand for full-text articles, particularly through interlibrary loan; and the uncertainty and questions regarding fair use and copyright compliance for articles shared among OhioLINK members (Diedrichs, 2001). In response to these challenges, OhioLINK sought a solution to "obtain licenses for journal use on a statewide basis at the publisher level maximizing the power and size of OhioLINK" (Diedrichs, 2001), which resulted in the creation of the Electronic Journal Center, the local storage server that hosted the licensed electronic journal collection accessible to all OhioLINK members.

The OhioLINK Electronic Journal Center (EJC) is a tool created to improve dramatically our use of scholarly journals beyond the use of print journals. The EJC is an OhioLINK operated software and hardware site designed to aggregate the electronic journals licensed from multiple publishers (Sanville, 2001, p. 3).

In essence, the EJC is a locally developed and maintained platform for electronic journals, accessible to all authorized users in the OhioLINK consortium. In April 1998, the EJC was launched with its first available collections from both Elsevier and Academic Press (Sanville, 2001).

In addition to increasing access to content and reducing cost of journal subscriptions for OhioLINK members, the questions of archiving content also was taken into consideration. For 
nearly all licenses, perpetual archival rights were negotiated and included (Diedrichs, 2001). The archiving of the content was achieved through the EJC by loading and storing the data on local servers (Diedrichs, 2001). Rather than relying on a publisher or third party, the OhioLINK consortium is responsible for maintaining, preserving and archiving the perpetual rights content on its local servers.

By September 2000, there were over 3,000 journal titles and over 1.9 million articles in the EJC from some of the largest and most renowned academic publishers including Elsevier, Sprinter-Verlag, and Wiley, making the EJC one of the largest locally stored electronic journal collections in the United States (Diedrichs, 2001). During its initial years of creation, usage of content at the EJC grew rapidly from 280,000 articles downloaded in the first 12 months of operation, to 740,000 by the second 12 months, and reaching 1.4 million articles downloaded annually by April 2001, an explosion of $400 \%$ growth in the first 3 years of operation (Sanville, 2001).

Previous research on the OhioLINK EJC usage was conducted prior to 2007, when the usage data for this article begins. In 2006, Nicholas and Huntington examined data obtained from a range of publisher platforms from Blackwell Synergy, Elsevier, Emerald, and Oxford University Press, as well as the OhioLINK EJC. Nicholas and Huntington (2006) looked specifically at the usage of each journal that comprised the OhioLINK Big Deal packages available through the EJC. In their study, Nicholas and Huntington (2006) found that virtually everything available was used, but there was a distinct concentration of usage on a small percentage of titles. Among the journal titles, 5\% accounted for over one-third of usage, while half of all journal titles account for only $7 \%$ of use (Nicholas \& Huntington, 2006). 
Connell, Rogers, and Diedrichs (2005) researched the use of the EJC by students, faculty and staff at Ohio State University, studying at not only frequency of use, as Nicholas and Huntington had investigated, but also looking at the reasons students, faculty, and staff accessed the articles and the pathways they followed to find and obtain the electronic journals. Based on the survey, which was collected during the fall of 2002 (Connell et al., 2005), though the primary use of articles in the EJC was unsurprisingly for a class paper or project, how patrons found the article varied with some interesting behaviors. Of survey respondents, $32 \%$ found an article by browsing a particular journal issue in the EJC (Connell et al., 2005). Another 25\% used the EJC search option to enter a search term and view results (Connell et al., 2005). Eleven percent arrived at the article through a citation with a clickable link, whereas $10 \%$ found a citation in a print source, and only 9\% found a citation in an online source without a clickable link (Connell et al., 2005).

The landscape for how articles are found and the pathways users follow to access journal articles online has changed significantly since the Connell, Rogers and Diedrichs (2005) survey in 2002. Though Nicholas, Huntington, Jamali, Rowlands, and Fieldhouse (2009) explored the information seeking behavior of students via OhioLINK platforms such as the EJC, the data collected, from January 2005 to April 2006, lacked insight into referral URL and links, or specific data on where users come from prior to accessing EJC content. To connect users to digital content, libraries must go beyond the model of a library catalog, designed for locating physical collections, and not only embrace a vast range of tools that connect content to users, but also embrace the changing proclivity of users to favor tools that function like those available outside of the library. 
In addition to the core integrated library system, libraries routinely purchase OpenURL link resolvers, federated search platforms, and electronic resource management systems. Libraries have shown a strong interest in a new generation of discovery-layer interfaces that work more like some of the popular destinations on the Web such as Amazon, moving away from the older style of Web-based catalogs. (Breeding, 2009. p.58)

Whether using library-provided tools such as an online journal list or a web-scale discovery system, or externally developed products such as Google Scholar, users today have a multitude of ways with which they can access digital content. For content providers, such as publishers or locally hosted platforms, understanding not only the behavior of users but also the ecosystem of discovery that users play in is critical to ensure that content remains accessible and discoverable.

The history and development of the EJC took a turn for the worse in February 2009 when the OhioLINK data-storage system, which notably hosted all of the EJC content, experienced a catastrophic failure.

Beginning Wednesday afternoon, February 4, the OhioLINK computer disk storage system suffered a widespread, and supposedly not possible, multiple component failure affecting all major services with the exception of the OhioLINK Library Catalog. We have restored all services except the Electronic Journal Center (EJC). Restoration of the EJC remains under vigorous analysis, but unfortunately we know that any solution will not be immediate. In light of this, we are taking immediate steps to provide alternative access to the resources of the EJC through the various Web sites of the EJC journal publishers (Sanville, 2009).

This failure rendered the EJC content inaccessible for a period of time and resulted in OhioLINK members directing their patrons to access e-journal content from the publisher platforms. Prior to the hardware failure, not all OhioLINK institutions had complete access to OhioLINK's Elsevier subscriptions at ScienceDirect. The hardware failure resulted in all OhioLINK institutions being granted complete access to the OhioLINK Elsevier subscriptions at 
ScienceDirect (Sanville, 2009). Six days after the hardware failure, all OhioLINK resources, except content in the EJC, were fully restored (OhioLINK, 2009). This included other digital content OhioLINK provides, such as the Electronic Theses and Dissertation Center, the E-Book Center, and the Digital Media Center (OhioLINK, 2009). Not until March 18, 2009, almost a month after the initial hardware failure, was content fully restored at the EJC (OhioLINK, 2009).

Today, the EJC hosts nearly 1,000 journals from approximately 50 publishers. In June 2011, the 15 millionth article was added to the EJC (OhioLINK, 2011). The EJC continues to serve as a place where OhioLINK users can access and download journal articles from OhioLINK subscriptions.

\section{History of Elsevier's ScienceDirect}

Back in the late 1990s, during the same period that OhioLINK was developing and launching the EJC, Elsevier, the prominent publisher of scientific, technical and medical information, was developing and launching an electronic journal platform of its own. In 1995, Elsevier began offering 1,100 of its journals in electronic form to its subscribers (Reed Elesvier NV, 2011). Only one year prior to the launch of the EJC, Elsevier launched ScienceDirect, an online platform through which its 1,200 journals (at the time) were made available electronically (Reed Elsevier NV, 2011).

In those early days, Elsevier sought to balance the tension between maintaining the core business and innovating and adapting to a changing publishing environment. As Paul Evans of Elsevier Advanced Technology wrote for those competing in the publishing industry, particularly in science, technology and medicine, "enthusiastic experimentalism has to exist alongside the mature realism of a traditional industry and the tension between the two will finally only be 
resolved in the adoption of the most successful business models" (2001, p. 99). To maintain both an efficient and sustaining business and an entrepreneurial culture focused on innovation, Elsevier strategically restructured its business to accommodate both by developing new ventures, such as ScienceDirect, outside of its core publishing units (Evans, 2001).

By 2009, ScienceDirect grew to more than just an experimental side business. ScienceDirect held almost 9 million articles and over 4,700 e-books. Globally, over 11 million researchers across 200 countries used Elsevier's research tools, which include both ScienceDirect and the database Scopus (Datamonitor, 2009). Furthermore, by 2009 ScienceDirect had become a key brand for Reed Elsevier, parent company to Elsevier (Datamonitor, 2009) affording Elsevier a competitive advantage over other publishers.

In 2009, Elsevier moved beyond simply looking at enhancements to the functionality of the ScienceDirect platform. It looked more holistically at scholarly communication and dissemination in the digital age, launching the Article of the Future Project (Aalbersberg, Heeman, Koers, \& Zudilova-Seinstra, 2012). In addition to enhanced presentation and usability for engaging with the article content online, the Article of the Future offers the ability to include embedded digital content, such as ArcGIS maps for earth sciences research; provides readers with embedded related information providing additional context; and provides access to datasets on which the article research is based (Aalbersberg, et al., 2012). Elsevier's Article of the Future Project has demonstrated how scholarly communication has evolved in the digital age, through enhanced context, access to datasets, and visualization of research.

\section{Methodology}

This research project set out to compare electronic journal usage of OhioLINK patrons at both the EJC and ScienceDirect from 2007 through 2013. In addition to the interesting parallel 
history between OhioLINK's Electronic Journal Center and Elsevier's ScienceDirect platform, Elsevier's ScienceDirect platform was selected for evaluation out of practicality. Out of all the OhioLINK subscription content available at both the EJC and the vendor or publisher platform, ScienceDirect offered both easily retrievable access to consortium wide usage statistics and a large set of ejournals to evaluate.

To compare usage of content at ScienceDirect and the EJC, usage reports were retrieved from both platforms. Data retrieved encompasses usage by all OhioLINK member libraries, not simply a single institution. Because the earliest available usage reports at ScienceDirect were from 2007, comparison between usage of the EJC and ScienceDirect began with usage from January 2007. Usage reports retrieved from ScienceDirect were COUNTER (Counting Online Usage of Networked Electronic Resources), JR1 reports (Journal Reports 1). COUNTER is a code of practice for vendors and platform hosts that specifies "the content, format, delivery mechanisms and data processing rules for a set of core usage reports that are easily implemented by vendors and easily understood by librarians" (COUNTER FAQs, 2014). Usage reports retrieved from the EJC are unfortunately not COUNTER-compliant. The usage reports retrieved from the EJC do measure the same data as the COUNTER JR1 report, the number of successful full-text article requests by month. However, unlike the JR1 COUNTER reports, the EJC data is not downloadable in a format consistent with COUNTER. Notably, data must be downloaded for each month, rather than by calendar year, with data formatted by month, as COUNTER provides. For this research, Elsevier full-text article requests from the ECJ were downloaded for each month, from January 2007 to December 2013, and aggregated and reformatted by the author into a report consistent with COUNTER JR1 formatting. 
Although the list of titles accessible at the EJC and at ScienceDirect should theoretically be consistent by year, these lists did not always match. For example, a journal title may be identified in the EJC as an Elsevier title, although that title may no longer exist at ScienceDirect. Mismatches like these occasionally occurred when journals were formerly published by Elsevier and had since been sold to another publisher, but the original metadata at the EJC has not been updated with the new publisher information. When mismatches occurred, titles or ISSNs from either the EJC or ScienceDirect without a corresponding match in the other platform were removed from analysis. In some cases, a title or ISSN number had changed, but the update was not reflected in one of the title lists (most often in the EJC title list.) An effort was made to identify the corresponding title or ISSN number in the other title list. If a match could not be found, the title was removed from analysis. In order to ensure an accurate comparison of usage by titles, the title lists between the EJC and ScienceDirect were compared and scrubbed to be identical by year.

The number of Elsevier journals available at both the EJC and ScienceDirect has increased over time. In 2007, there were 1,910 journal titles that matched at the EJC and ScienceDirect. By 2013, the number of matching titles had increased 42\% to 2,705 journal titles. Because the number of titles has increased overtime, allowing for the potential to increase usage, the usage data needed to be normalized in order to account for the increase in the number of journal titles per year. Usage data for both the EJC and ScienceDirect was normalized to reflect usage per 100 journal titles.

Once the data was normalized, a simple linear regression analysis was performed on the EJC and ScienceDirect usage from January 2007 to December 2013. The slope of the regression lines, intercepts of the two lines, and the R-squared values were all calculated. 
Table 1. Number of Matching Journals Titles at the EJC and ScienceDirect by Year

\begin{tabular}{|l|l|}
\hline Year & Title Count \\
\hline 2007 & 1910 \\
\hline 2008 & 2050 \\
\hline 2009 & 2084 \\
\hline 2010 & 2154 \\
\hline 2011 & 2243 \\
\hline 2012 & 2245 \\
\hline 2013 & 2705 \\
\hline
\end{tabular}

\section{Findings}

Figure 1. Usage per 100 titles at the Electronic Journal Center and ScienceDirect from 20072013

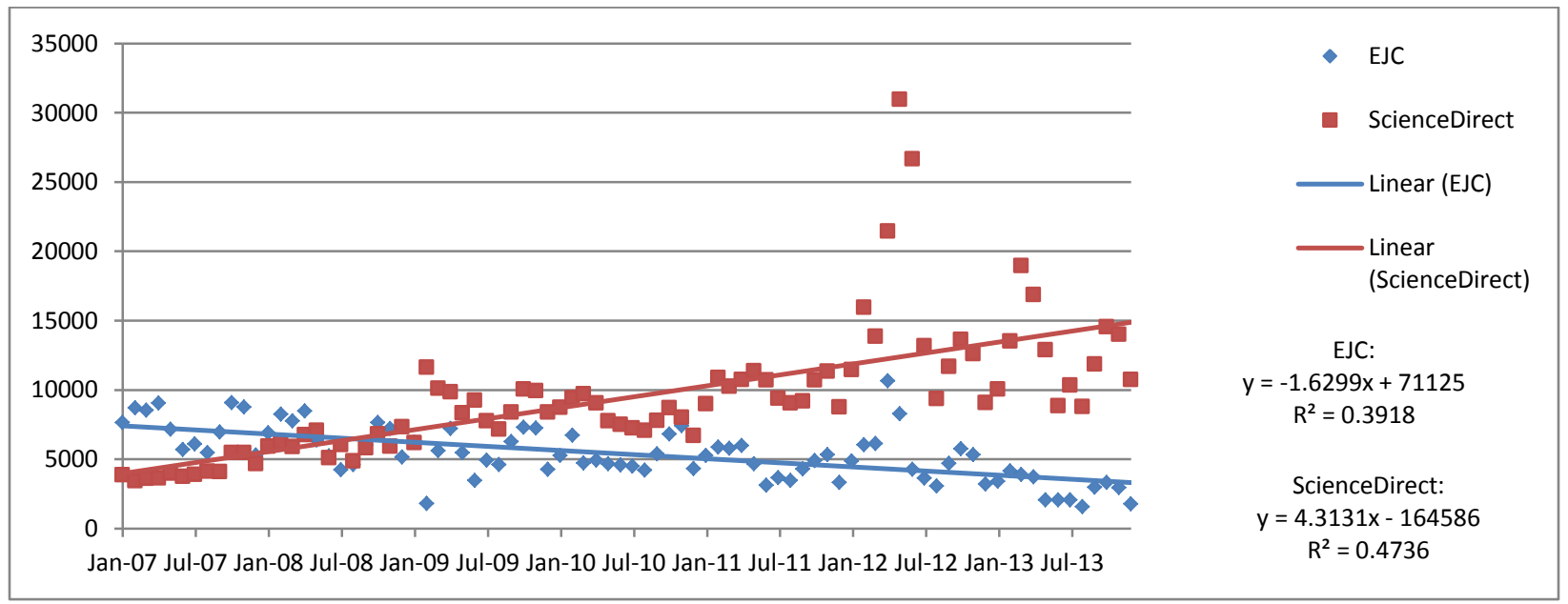

In January 2007, the EJC saw usage nearly two times greater than that of ScienceDirect for the same titles among all OhioLINK institutions. Usage among OhioLINK institutions remained greater at the EJC than at ScienceDirect throughout 2007 and into 2008 until May. In 
May 2008, usage per 100 titles at the EJC was 6,382, whereas usage at ScienceDirect was about 1.1 times higher, with 7,088 successful full-text downloads per 100 titles. The months that followed in 2008 fluctuated between the EJC and ScienceDirect exhibiting higher usage.

Table 2. Usage per 100 titles at the EJC and ScienceDirect in 2008

\begin{tabular}{|l|l|l|}
\hline Month & EJC & Science Direct \\
\hline January & 6921 & 5948 \\
\hline February & 8252 & 6212 \\
\hline March & 7778 & 5912 \\
\hline April & 8482 & 6754 \\
\hline May & 6383 & 7088 \\
\hline June & 5237 & 5110 \\
\hline July & 4246 & 6043 \\
\hline August & 4610 & 4886 \\
\hline September & 6021 & 5820 \\
\hline October & 7655 & 6814 \\
\hline November & 7213 & 5939 \\
\hline December & 5150 & 7346 \\
\hline
\end{tabular}

What is notable about this period is the decline in usage at the EJC and the rise in usage at ScienceDirect began occurring months before the devastating hardware failure of OhioLINK systems that rendered the EJC unavailable from February 4, 2009, to March 18, 2009. During that time, users were directed to the publishers' sites, such as Elsevier's ScienceDirect, in order to access EJC content.

It is expected that a sharp decline in usage at the EJC would occur for some period after the hardware failure in February of 2009, due to the lack of access to content at the EJC. However, as Chart 1 shows, the slope of the line that equates to the trend in usage at the EJC is negative (-1.6299x), demonstrating a steady decline in usage since January 2007. Furthermore, the intercept between the two regression lines for the EJC and ScienceDirect occurs not after the 
EJC hardware failure, but a few months prior, in August 2008, meaning users began to frequent content at ScienceDirect over viewing the EJC prior to being obligated to do so in February 2009. The shift in use from the EJC to ScienceDirect began to occur many months prior to the EJC hardware failure, suggesting that factors other than the EJC hardware failure led users to content at Elsevier's ScienceDirect.

Though usage fluctuated between the EJC and ScienceDirect prior to the EJC outage, after the outage, usage of Elsevier content at the EJC never outperformed usage at ScienceDirect. In fact, as the number of titles added to the collection grew, and as usage at ScienceDirect continued to grow, usage at the EJC has steadily declined. The slope of the line that equates to the trend in usage at ScienceDirect per 100 titles is 4.3131, which increases at a rate of 5.9 more than that of the EJC for the same period of time.

In addition to noting the occurrence of hardware failure and lack of access to content at the EJC in February and March of 2009, it is also noted that there is a significant spike in usage at ScienceDirect from April-June 2012. Although higher usage may be expected during these months due to the academic calendar ramping up for finals and the end of the school year, this spike in usage was attributed to only one OhioLINK institution. When investigated further, the spike in usage was attributed to an incident of unauthorized access and use of ScienceDirect at that institution (L. Kinner, personal communication, March 22, 2013).

Figure 2. Rolling 12-month average usage per 100 titles at the Electronic Journal Center and ScienceDirect from 2008-2013 


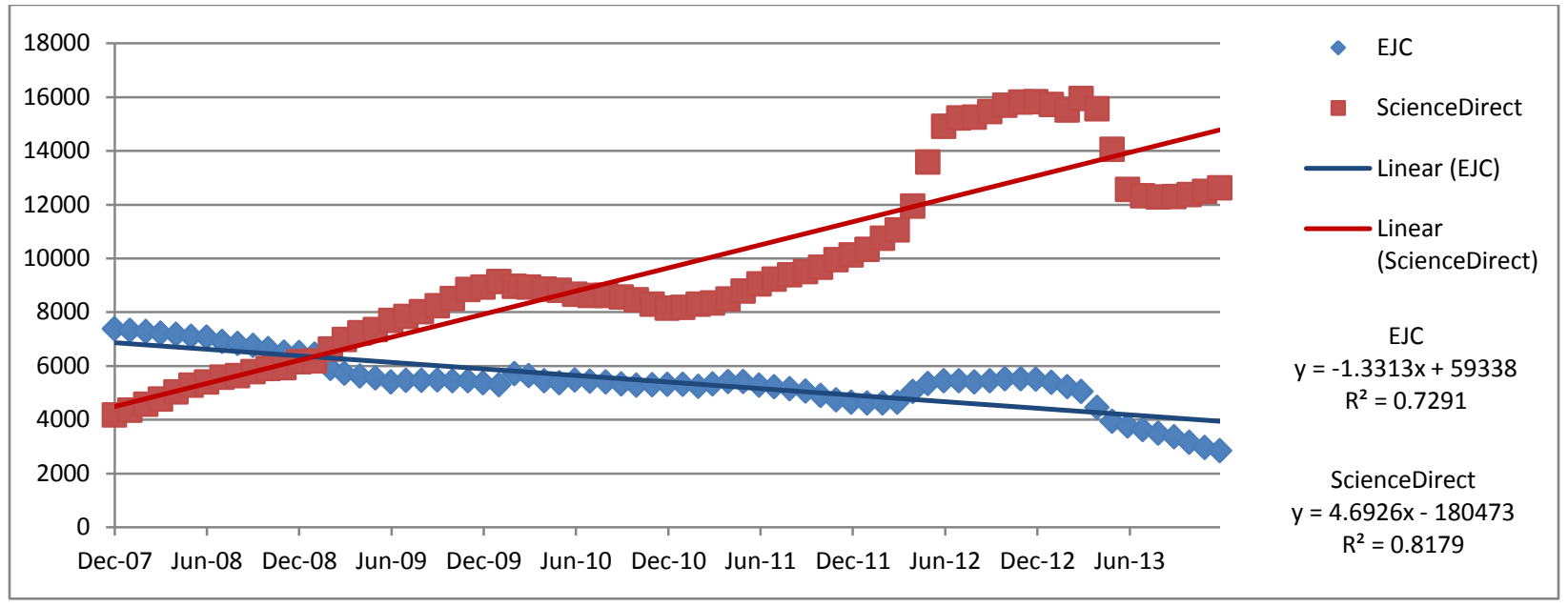

The rise in usage at ScienceDirect and decline of usage at the EJC becomes even more pronounced when looking at Chart 2, which shows a 12-month rolling average of usage. Because the trend in usage commonly fluctuates over the course of an academic year, such as showing higher usage during finals and lower usage during summer vacation, calculating and graphing a 12-month rolling average can account for the fluctuations and help to illustrate an overall trend.

The 12-month rolling average is calculated by taking the average usage for a 12-month period of time. In Chart 2 the initial calculation for the December 2007 data, is the average of usage, per 100 titles for January through December 2007. The second data point for January 2008 takes the average usage, per 100 titles, for February 2007-January 2008. This calculation progresses in the same manner through December 2012, taking into account the average of the current month plus the 11 previous months.

As Chart 2 illustrates, the plot points for usage at both the EJC and at ScienceDirect show a much smoother trend. Using a 12-month rolling average is further illustrated as suitable based on the improved R-squared values for both the EJC and ScienceDirect regression lines in this chart. The R-squared value for both the EJC and the ScienceDirect regression line in Chart 2 fall 
closer to 1 , at 0.73 and 0.82 respectively, reflecting a stronger relationship between the data points and the regression line.

\section{Implications}

With the rise of discovery systems and tools that connect users to online content, understanding which platforms users more frequently select over others that may provide the same content serves a practical purpose. Link resolvers like Serials Solutions 360 Link and discovery-layer products like EBSCO Discovery Service enable libraries to rank platforms with identical content. When librarians and discovery-tool administrators are given a choice of which platform among many to select as the primary link, an analysis such as the one conducted above can aid in the decision-making. By replicating the research conducted in this article at the individual institution level, librarians can better assess and predict user preferences for platforms.

If the promoted link is the one that already experiences higher usage, then further promotion of the platform may result in an even more significant gap between usage at one platform over another. This, in turn, raises the question of what is the value and role of the platform that exhibits a much lower usage? Furthermore, can and should the platform be eliminated from the collection?

For a locally developed platforms or tools such as the OhioLINK EJC, if usage directly at the EJC is significantly lower than usage for the same content found elsewhere, the question becomes, is it prudent to continue to upgrade and develop the platform, when external partners and commercial vendors have the resources and means to create platforms users are drawn to? With limited funding for academic libraries, homegrown systems can be assessed in multiple 
ways, one of which could be whether or not users are accessing the homegrown system over similar commercial products on the market.

Whether looking at the EJC in comparison to ScienceDirect, or two other platforms with identical content, the recommended further research would be to explore who the users are who do continue to use the less popular platform, and why they choose to use that platform over the other options. Perhaps there are functions for specific types of research or use that the lesspopular platform performs better. If so, then the less-popular platform may be promoted by the libraries as a specialized or niche platform to those specific users and bibliographic instruction for general users can focus on the more popular platform.

\section{References}

Aalbersberg, I., Heeman, F., Koers, H., \& Zudilova-Seinstra, E. (2012). Elsevier's Article of the Future enhancing the user experience and integrating data through applications. Insights: The UKSG Journal, 25(1), 33-43. doi:10.1629/2048-7754.25.1.33

Breeding, M. (2009). Next Generation Library Automation: Its Impact on the Serials Community. The Serials Librarian, 56(1-4), 55-64. doi: 10.1080/03615260802679028

Connell, T. H., Rogers, S. A., \& Diedrichs, C. P. (2005). OhioLINK electronic journal use at Ohio State University. portal: Libraries and the Academy, 5(3), 371-390. doi:

10.1353/pla.2005.0033

COUNTER FAQs (2014, March). Retrieved April 21, 2014 from

http://www.projectcounter.org/faqs.html

Datamonitor. (2009, October 30). Reed Elsevier NV Company Profile. New York, NY: Datamonitor.

Diedrichs, C.P. (2001). E-journals: the OhioLINK experience. Library Collections, Acquisitions, and Technical Services, 25(2), 191-210.

Evans, P. M. (2001). Advances into electronic publishing: Engineering information and Elsevier Advanced Technology. Knowledge and Process Management, 8(2), 99-104. 
Nicholas, D., \& Huntington, P. (2006). Electronic journals: are they really used? Interlending \& Document Supply, 34(2), 48-50. doi: 10.1108/02641610610669723

Nicholas, D., Huntington, P., Jamali, H.R., Rowlands, I., \& Fieldhouse, M. (2009). Student digital information-seeking behaviour in context. Journal of Documentation, 65(1), 106-132.

OhioLINK. (2009, February 11). OhioLINK Resources Restored Following Hardware Upgrade. Retrieved June 10, 2013 from http://olc7.ohiolink.edu/whatsnew/archives/000304.html

OhioLINK. (2009, March 18). Electronic Journal Center Now Fully Restored. Retrieved June 10, 2013 from http://olc7.ohiolink.edu/whatsnew/archives/000318.html

OhioLINK (2011, June 3). Fifteen Millionth Article Added to Electronic Journal Center. Retrieved November 20, 2012 from: http://olc7.ohiolink.edu/whatsnew/archives/000408.html

Reed Elsevier NV. (2011). In Notable Corporate Chronologies. Detroit: Gale. Retrieved from http://bi.galegroup.com

/global/article/GALE\%7CI2501150637/5068fd4bdb0b4895029689918aeec456

Sanville, T. J. (2001). Use of Electronic Journals in OhioLINK'S Electronic Journal Center. IFLA Conference Proceedings, 1-16. Retrieved from: http://search.ebscohost.com/login.aspx?direct=true \&db=lih\&AN=43883614\&site=ehost-live

Sanville, T. (2009, February 8). EJC update to the OhioLINK community of students, faculty, and staff. Retrieved June 10, 2013 from http://olc7.ohiolink.edu/whatsnew/archives/000303.html 